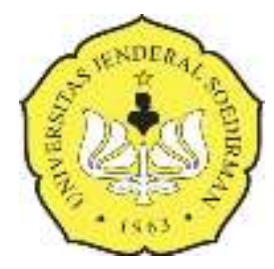

PAJU Volume 1 Nomor 12019

PHYSICAL ACTIVITY JOURNAL

http://jos.unsoed.ac.id/index.php/paju

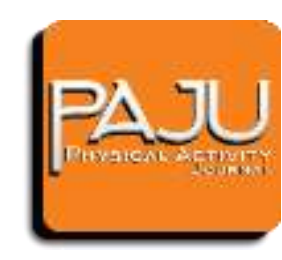

\title{
Pengaruh Model Pembelajaran Kooperatif Tipe Stad Terhadap Keterampilan Passing Bawah Dalam Permainan Bola Voli Di SMA Islam Al-Fardiyatussa'adah Citepus Palabuhanratu
}

\author{
Faiz Faozi ${ }^{1}$, Hasan Sanusi ${ }^{2}$, Arfin Deri Listiandi ${ }^{3}$ \\ 1,2 Pendidikan Jasmani Kesehatan dan Rekreasi, STKIP Bina Mutiara Sukabumi \\ ${ }^{3}$ Fakultas IImu-IImu Kesehatan, Universitas Jenderal Soedirman, Indonesia \\ email: faizfaozi@gmail.com¹, sanusihasan823@gmail.com² , arfinderilistiandi@gmail.com³ \\ DOI: https://doi.org/10.20884/1.paju.2019.1.1.2001
}

\begin{abstract}
Abstrak
Permasalahan dalam penelitian ini adalah masih kurangnya kemampuan siswa dalam passing bawah permainan bola voli. Tujuan penelitian ini adalah mengetahui pengaruh pembelajaran model kooperatif tipe STAD terhadap keterampilan passing bawah dalam permainan bola voli di SMA Islam Al-Fardiyatussa'adah Citepus Palabuharatu. Metode yang digunakan dalam penelitian ini adalah metode eksperimen dengan desain penelitian one-grup pretetst-posttest design. Poulasi penelitian sebanyak 84 siswa dan diambil untuk sempel satu kelas dengan jumlah 35 siswa. adapun teknik sempel yang digunakan dalam penelitian ini adalah Simple Random Sampling. Instrument penelitian menggunakan tes passing bawah bola voli menurut Fauzi (2011). Data hasil belajar dikumpukan melalui pretest dan posttest. Pada data hasil pretest diperoleh nilai rata-rata 22.51 sedangkan data hasil posttest diperoleh nilai rata-rata 27.34. Untuk menentukan data berdistribusi normal atau tidak,maka analisis data dilakukan uji t berpasangan pada pretest dan posttest. Hasil analisis dibuktikan pada taraf signifikan $a=0,05$. Maka hasil dari uji t yaitu memiliki nilai $\mathrm{t}=9.269$ dan sig $000<0,05$ maka Ho ditolak atau dapat pengaruh yang signifikan. sehingga analisis dari hasil deskripsi data pretest dan posttest mengenai pengaruh model pembelajaran kooperatif tipe STAD terhadap keterampilan passing bawah dalam permainan bola voli memiliki peningkatan.
\end{abstract}

Kata Kunci : Passing Bawah, Kooperatif Tipe Student Team-Achievment Devision (STAD), Permainan Bola Voli

\begin{abstract}
The problem in this research is the lack of students' ability in passing under the volleyball game. The purpose of this study was to determine the effect of STAD type cooperative learning model on lower passing skills in volleyball games at Islamic High School Al-Fardiyatussa'adah Citepus Palabuharatu. The method used in this study is an experimental method with a one-group pretest-posttest design research design. The research population was 84 students and taken to sample one class with a total of 35 students. The sample technique used in this research is Simple Random Sampling. The research instrument uses a volleyball underpass test according to Fauzi (2011). Learning outcomes data collected through pretest and posttest. In the pretest data obtained an average value of 22.51 while the posttest data obtained an average value of
\end{abstract}


27.34. To determine whether the data is normally distributed or not, the data analysis is done by paired t test on the pretest and posttest. The results of the analysis are proven at a significant level $a=0.05$. Then the results of the $t$ test that has a value of $t=9.269$ and sig $000<0.05$ then Ho is rejected or can be a significant influence. so the analysis of the results of the description of the pretest and posttest data regarding the effect of the STAD type cooperative learning model on the under passing skills in volleyball games has increased.

Keywords: Cooperative Student Team-achievment Devision (STAD) type, volleyball game.

\begin{tabular}{|c|c|c|c|}
\hline & : $\quad$ Prodi PJKR STKIP Bina Mutiara Sukabumi & $\begin{array}{l}\text { e-ISSN } \\
\text { p-ISSN }\end{array}$ & $\begin{array}{l}: 2686-5807 \\
: 2686-5793\end{array}$ \\
\hline $\begin{array}{l}\text { E-mail } \\
\text { No. Telp./Hp }\end{array}$ & $\begin{array}{l}\vdots \\
\vdots\end{array}$ faizfaozi@gmail.com & & \\
\hline
\end{tabular}

\section{PENDAHULUAN}

Pendidikan merupakan salah satu pembelajaran pengetahuan, keterampilan, dan kebiasaan sekelompok orang yang diturunkan dari satu generasi kegenerasi berikutnya melalui pengajaran, pelatihan. Pendidikan jasmani salah satu proses pendidikan yang memanfaatkan aktivitas fisik yang dilakukan secara sadar dan sistematik melalui berbagai kegiatan dalam rangka memperoleh kemampuan dan keterampilan jasmani, pertumbuhan, kecerdasan, emosional, dan pembentukan watak. Pendidikan jasmani, olahraga kesehatan (penjasorkes) merupakan bagian integral dari pendidikan secara keseluruhan, bertujuan untuk mengembangkan aspek kebugaran jasmani, melalui pola hidup sehat dan pengenalan lingkungan bersih Depdiknas (2006). Kurikulim 2013 dirancang untuk memperkuat kompetensi peserta didik dari sisi pengetahuan, keterampilan, dan sikap secara untuh. Pendidikan Jasmani, Olahraga, dan Kesehatan (PJOK) pada hakikatnya adalah proses pendidikan yang memanfaatkan aktivitas fisik untuk menghasilkan perubahan kemampuan siswa dalam kualitas individu, baik dalam bentuk fisik, mental, serta emosional.

Perlu ditekankan harapan dari penyelenggaraan pendidikan jasmani di sekolah salah satunya yaitu berkontribusi tehadap pengembangan potensi siswa melalui keterampilan-keterampilan yang dimiliki oleh peserta didik sehingga keterampilan yang dimiliki membawa kepada kesejahteraan hidupnya kelak. Proses pembelajaran pendidikan jasmani lebih mengutamakan pada elaborasi hubungan kuat antara sisi sosial-emosional, kognitif reflektif, gerak keterampilan siswa, dan sisi psikologis siswa. Pangrazi dan Daeur (dalam Stephani, 2014) memaparkan bahwa:

Physical education is a part of the general educational programs that contributes, primarily through movement experiences, to the total growth and development all of children. Physical education is defined as education of and through movement, and must be cunducted in a manner that merits this meaning.

Maksud dari pernyataan di atas ialah, pendidikan jasmani merupakan bagian dari program pendidikan umum yang memberikan kontribusi, untuk pertumbuhan dan perkembangan anak terutama 
melalui pembelajaran pengalaman gerak. Pembelajaran pendidikan jasmani didefinisikan sebagai pendidikan melalui gerak. Kemudian pembelajaran pendidikan jasmani haruslah memuat nuansa pendidikan yang utuh dalam pengembangan aspek jasmani, rohani, dan sosial. Pendidikan melalui aktifitas jasmani diharapkan memberikan pengalaman belajar yang nyata terhadap siswa.

Melalui pembelajaran pendidikan jasmani, diharapkan siswa akan memiliki keterampilan dan kecakapan hidup sebagai bekal menghadapi dunia kerja dan menjalani profesi masing-masing, dengan keterampilan akan menentukan keberadaan manusia tersebut. Pada dasarnya semua siswa memiliki beberapa keterampilan, hanya saja perlu latihan dan pengalaman untuk menghasilkan keterampilan yang baik dan mempelajari keterampilan yang lain. Seperti yang dikemukakan oleh Schmidt \& Wrisberg (2000) menjelaskan bahwa to achieve proficiency in other skill, we need considerably more practice. Only then are we able to dctect important envipromental feature (and ignore others) and produce the kind of movement that result in consistent goal achievement. Artinya untuk mencapai kemahiran dalam keterampilan lain, diperlukan lebih banyak latihan atau praktek, sehingga dapat diketahui dan diperoleh jenis gerakan yang menghasilkan pencapaian tujuan dari lingkungan. Keterampilan menjadi sangat penting dipelajari oleh siswa, namun dalam pendidikan jasmani siswa tidak hanya dituntut terampil dalam berolahraga, akan tetapi siswa diharapkan dengan pembelajaran melalui gerak memiliki pemahaman mengenai konsep-konsep dalam pembelajaran tersebut dan memiliki muatan nilai sosial seperti, disiplin, kerjasama, saling tolong-menolong dan bersahabat.

Materi bola voli pada mata pelajaran pendidikan jasmani, olahraga, dan kesehatan merupakan materi yang secara tertulis tercantum dalam silabus pendidikan kurikulum 2013, yang berarti guru bahwa penjas wajib memberikan atau setidaknya mengenalkan materi tersebut kepada peserta didik. Materi bola voli pada mata pelajaran pendidikan jasmani, olahraga, dan kesehatan merupakan materi yang secara tertulis tercantum dalam silabus pendidikan kurikulum 2013, yang berarti guru bahwa pendidikan jasmani wajib memberikan atau setidaknya mengenalkan materi tersebut kepada peserta didik. Hal tersebut dapat dilakukan dengan berbagai cara yaitu dengan melakukan praktik langsung dilapangan maupun dengan menggunakan media belajar lainnya seperti melihat video dan lain-lain. Adapun dalam proses pembelajaran bola voli siswa harus mengamati, menanya, mengeksplorasi, mengasosiasi, dan mengkomunikasikan. Pada setiap pembelajaran khususnya olahraga bola voli.

Cabang olahraga bola voli adalah salah satu permainan yang kompleks yang tidak mudah dilakukan oleh setiap orang, karena dalam setiap permainan bola voli dibutuhkan koordinasi gerak yang benar-benar bisa diandalkan untuk semua gerakan dalam permainan bola voli itu sendiri. Adapun teknikteknik dasar permainan bola voli dengan tujuan untuk mendapatkan skor. Teknik dasar bola voli meliputi: (1) passing bawah, passing atas, (2) servis bawah, servis atas (3) smash dan (4) bendungan (block). Teknik dasar passing bawah mempunyai peranan penting dalam permainan bola voli. Berdasarkan jenisnya, passing bola voli dibedakaan menjadi dua macam yaitu passing bawah dan passing atas. 
Pentingnya peranan passing maka harus diajarkan kepada siswa agar siswa memahami dan menguasainya, sehingga dapat melakukan passing dengan baik dan benar. Pengertian Passing Bawah bola voli merupakan teknik pada permainan bola voli yang mendasar, passing bawah digunakan sebagai langkah awal untuk menyusun pola serangan kepada regu lawan. Passing bawah menurut Subroto (2010) adalah, "Cara memainkan bola yang datang lebih rendah dari bahu dengan menggunakan kedua pergelangan tangan yang dirapatkan". Kegunaan dari passing bawah bola voli antara lain untuk menerima bola servis, menerima bola smash atau serangan dari lawan.

Masalah dalam penelitian ini masih banyak siswa yang belum bisa melakukan teknik Passing bawah pada saat pelaksanaan olahraga bola voli, Guru kurang menguasai Model-model pembelajaran dalam penjas sehingga pembelajaran menjadi sedikit membosankan, proses pembelajaran olahraga tidak menggunakan model-model pembelajaran khususnya model kooperatif. Model pembelajaran kooperatif merupakan proses belajar mengajar yang melibatkan kelompok-kelompok kecil yang memungkinkan siswa untuk bekerja atau belajar bersama-sama didalam kelompoknya untuk menyelesaikan suatu masalah atau tugas yang diberikan oleh guru. Kemudian Metzler (2000) menyatakan bahwa "Major theme for cooperative learning: The group has not achieved until all of its member have achieved". Artinya ketika suatu kelompok dinyatakan tidak berhasil, maka anggota lain dalam kelompok membantu sampai seluruh anggota dalam kelompok tersebut berhasil. Karena siswa yang belajar atau bekerja secara kelompok kecil akan lebih baik dalam menguasai materi yang disampaikan oleh guru dibandingkan siswa bekerja atau belajar sendiri. Hal tersebut senada dengan yang diungkapkan oleh Wang (2012) mengakatakan bahwa "Subtantial evidence exixts to support the idea that student working in small cooperative group can material presented by the teacher better than student working on their own". Jadi model pembelajaran kooperatif ialah seperangkat strategi dalam pengajaran yang memberikan atribut kunci, yang paling penting dalam model pembelajaran ini adalah mengelompokan siswa ke dalam beberapa kelompok belajar dalam jumlah tertentu, waktu dan tugas tertentu. Dengan harapan semua siswa yang mengikuti pembelajaran dapat berkontribusi terhadap proses maupun hasil belajarnya, sehingga dalam model pembelajaran kooperatif diharapkan seluruh siswa aktif belajar baik dalam proses pembelajaran dan berani mengungkapkan gagasannya, seperti saling berinteraksi dengan sesama temannya ataupun meningkatkan hasil belajarnya.

Dalam pembelajaran kooperatif terdapat lima metode pembelajaran tim siswa, Slavin (2005) dalam Nurlita, 2009:) menyebutkan:

Lima prinsip dalam metode PTS telah dikembangkan dan diteliti secara ekstensif. Tiga diantaranya adalah metode pembelajaran kooperatif yang dapat diadaptasikan pada sebagian besar mata pelajaran dan tingkat kelas. Student Team-Achievement Division (STAD), TeamGames-Tournament (TGT) dan Jigsaw. Dua yang lain dirancang untuk digunakan dalam mata pelajaran khusus pada tingkat kelas tertentu, yaitu Cooperative Integrated-Reading and Composition (CIRC) dan Team Accelerated Instruction (TAI). 
Dari ke lima metode pembelajaran tim siswa yang ada dalam pembelajaran kooperatif tersebut, peneliti memilih STAD sebagai metode pembelajaran siswa yang akan digunakan dalam proses penelitian, karena STAD merupakan metode yang paling sederhana. Menurut Slavin (2005) mengatakan bahwa "In STAD students are assigned to four-member learning teams which are mixed in performance level, sex and ethnicity". Artinya dalam pembelajaran kooperatif tipe STAD siswa dibentuk menjadi beberapa kelompok belajar dan setiap kelompok tersebut beranggotakan empat orang yang heterogen, jenis kelamin dan etnis atau latar belakangnya. Kemudian lebih lanjut Slavin (2005) menyatakan bahwa "Student Team Achievement Divison (STAD) merupakan suatu model pembelajaran untuk memotivasi siswa agar dapat saling mendukung dan membantu satu sama lain dalam menguasai kemampuan yang diajarkan oleh guru". Dapat disimpulkan dari pernyataan tersebut ketika kelompok yang mempunyai nilai yang paling besar, diharapkan akan menjadi motivasi bagi kelompok yang mempunyai nilai lebih kecil, kemudian apabila terdapat salah satu anggota dari setiap kelompok mengalami kesulitan dalam proses pembelajaran anggota lain bertanggung jawab untuk membantu anggota yang mengalami kesulitan tersebut sehingga tujuan dari pembelajaran tersebut akan tercapai.

Belajar merupakan suatu proses yang ditandai dengan adanya perubahan pada diri seseorang. Perubahan sebagai hasil proses belajar dapat ditunjukan dalam berbagai bentuk seperti pengetahuannya, pemahamannya, sikap dan tingkah lakuknya, keterampilannya, kecakapannya, dan kemampuannya, daya reaksinya, daya penerimaannya, dan lain-lain sebagai asfek yang terdapat dalam individu. Hamalik (dalam Komang Kartika dkk, 2014) belajar adalah modifikasi atau memperteguh kelakuan melalui pengalaman. Djamah dan dahlan (dalam Febrianto dkk, 2018) mengemukakan bahwa belajar adalah serangkaian kegiatan jiwa raga untuk memperoleh suatu perubahan tingkah laku sebagai hasil dari pengalaman individu dalam interaksi dengan lingkungannya menyangkut kognitif, afektif, dan psikomotor.

Dalam konteks pembelajaran terdapat dua komponen penting, yaitu guru dan peserta didik yang saling berinteraksi. Pembelajaran didefinisikan sebagai pengorganisasian atau penciptaan atau pengetahuan suatu kondisi lingkungan yang sebaik-baiknya yang memungkinkan terjadinya belajar pada peserta didik. Dimyati dan Mudjiono (dalam Juliantine dkk, 2015) Pembelajaran adalah kegiatan guru secara terprogram dalam desain instruksional, untuk membuat siswa belajar secara aktif, yang menekankan pada penyediaan sumber belajar. Knirk dan Gustafon (dalam Juliantine dkk, 2015) Pembelajaran adalah segala kegiatan yang dirancang oleh guru untuk membantu seseorang untuk mempelajari suatu kemampuan dan atau nilai yang baru dalam suatu proses yang sistematis melalui tahapan rancangan, pelaksanaan dan evaluasi dalam konteks kegiatan pembelajaran.

Dalam kurikulum 2013 untuk tingkatan Sekolah Menengah Atas (SMA) terdapat materi bola besar, kemudian peneliti mengambil salah satu materi tersebut untuk diteliti yaitu pembelajaran bolabasket. Pada pembelajaran bolabasket yang menggunakan model pembelajaran kooperatif tipe STAD, siswa dihadapkan pada situasi lingkungan yang menuntutnya untuk menemukan solusi terbaik dalam 
menyelesaikan pembelajaran bolavoli, penampilan siswa dalam pembelajaran yang ditunjukan merupakan hasil dari pemahaman berpikir mereka, bukan berasal dari apa yang diberitahu oleh guru. Sehingga peran guru pada proses pembelajaran sebagai fasilitator yang menyajikan permasalahan gerak maupun permasalahan permainan, kemudian siswa memiliki peran penting dalam suatu proses pemecahan permasalahan dan siswa memiliki peran penting dalam proses pembelajaran.

\section{METODE}

Metode yang digunakan dalam penelitian ini adalah metode eksperimen. Peneliti menggunakan desain One-Group Pretest-Posttest Design dalam design ini terdapat pretest, sebelum diberi perlakuan, Sugiyono (2015). Dalam penelitian ini tahap perlakuan (Treatment) yang diberikan adalah menggunakan metode pembelajaran kooperatif tipe STAD khususnya pada materi Passing bawah dalam permainan bola voli di kelas XII SMA Islam AI-Fardiyatussa'adah. Pada saat pembelajaran pertama siswa diberikan perlakuan melakukan Pretest yaitu melakukan Passing bawah dalam permainan bola voli, setelah hasilnya ditemukan siswa melakukan perlakuan (treatment) dengan secara berkelompok dengan menggunakan metode pembelajaran kooperatif tipe STAD terhadap keterampilan Passing bawah dalm permainan bola voli, dan diakhiri dengan Posttest. adapun waktu dalam pelaksanaan nya yaitu menggunakan 3 kali seminggu sebanyak 12 kali pertemun.menurut Tite Juliantine, dkk (dalam Hadi dkk, 2007) berpendapat bahwa para pelatih telah sepakat, bahwa latihan 3 kali seminggu akan meningkatkan kekuatan tanpa ada resiko yang kronis. Dari pendapat para ahli di atas bahwa pemberian perlakuan (Treatment) dalam penelitian ini dilakukan sebanyak 12 kali pertemuan (4 minggu). Adapun pemberian perlakuan atau latihan yang berbentuk kegiatan permainan yang diberikan kepada siswa sebanyak 3 kali pertemuan dalam seminggu.

Populasi dari penelitian ini adalah seluruh siswa SMA Islam Al-Fardiyatussa'adah kelas X,XI dan XII, setiap kelas terdiri satu kelas pada setiap masing-masing kelasnya, dengan jumlah 84 siswa. Sampel dari penelitian adalah kelas XII SMA Islam AI-Fardiyatussa'adah yang terdiri dari 35 siswa dengan cara Simple Random Sampling (sederhana).Instrumen yang digunakan dalam penelitian ini adalah Battery test olahraga bola voli yang dikutip dari Fauzi (2011).Teknik analisis data dalam penelitian ini menggunakan statistik. Data yang terkumpul hasil tes awal dan tes akhir diolah dengan bantuan program computer SPSS for windows 16

\section{HASIL}

Data yang diperoleh dari hasil tes masih belum berarti dan bermakna apa-apa. Untuk mendapatkan kesimpulaan, maka data-data tersebut harus diolah dan dianalisis secara statistika. 
Tabel 1. Deskripsi Data Pretest dan Posttest

\begin{tabular}{ccccc}
\hline NO & & pretest & Pottest & gain \\
\hline 1 & Jumlah & 788 & 957 & 169 \\
\hline 2 & Rata-rata & 22.51 & 27.34 & 4.83 \\
\hline 3 & Simpangan Baku & 6.04 & 7.02 & 0.98 \\
\hline 4 & Skor Minimal & 13 & 16 & 3 \\
\hline 5 & Skor Maksimal & 36 & 45 & 9 \\
\hline
\end{tabular}

Berdasarkan tabel 1. tersebut, diketahui bahwa sebelum dilakukannya perlakuan (pretest) diperoleh sekor rata-rata 22.51 dengan simpang baku sebesar 6.04, setelah diberikan perlakuan dengan menggunakan model pembelajaran kooperatif tipe STAD, terjadi peningkatan hasil belajar keterampilan passing bawah sehingga rata-rata menjadi 27.34 dengan standar deviasi 7.02 .sehingga hasil analisi dari deskrisi data pretest dan posttest mengenai pengaruh model pembelajaran kooperatif tipe STAD terhadap keterampilan passing bawah dalam permainan bola voli memiliki peningkatan.

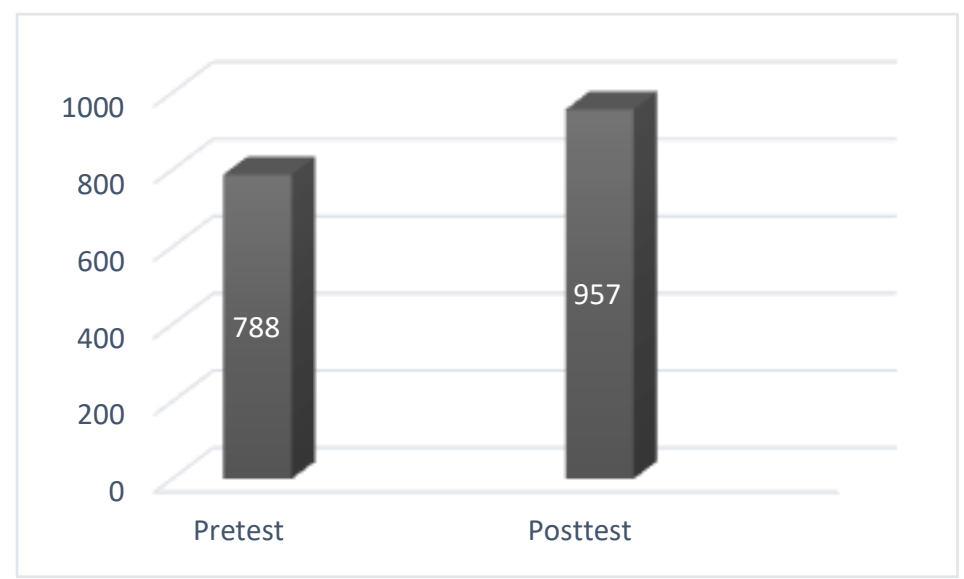

Gambar 1. Grafik Perbandingan Pretest-Posttest

Grafik diatas merupakan peningkatan setelah sempel diberikan perlakuan dengan menggunakan model pembelajaran kooperatif tipe STAD terhadap keterampilan passing bawah dalam permainan bola voli, Dengan memiliki jumlah skor pretest 788 dan jumlah sekor keseluruhan posttest 957.

Analisis data dilakukan dengan uji-t berpasangan (paired sample $t$ test) pada data pretest dan posttest. Hasil analisis dibuktikan pada taraf signifikan $\alpha=0,05$. Untuk mengetahui pengaruh model pembelajaran kooperatif tipe STAD terhadap ketterampilan passing bawah dalam permainan bola voli pada kelas XII SMA Islam AI-Fardiyatussa'adah citepus palabuhanratu, diuji dengan mencari pengaruh kemampuan passing bawah sebelum dan sesudah diberikan perlakuan dengan pemberian model pembelajaran kooperatif tipe STAD. Hasil uji-t diajukan pada tabel 2. dibwah ini. 
Tabel 2. Hasil Uji-t Kemampuan Passing Bawah

\begin{tabular}{llllll}
\hline & Mean & T & Df & Sig. (2-tailed) \\
\hline Pair & Model Pembelajaran STAD & 4.82857 & 9.269 & 34 & .000 \\
1 & Pre & & & & \\
& Post & & & & \\
\hline
\end{tabular}

Hipotesis:

$\mathrm{Ho}=$ Tidak terdapat pengaruh yang signifikan kooperatif tipe STAD terhadap keterampilan passing bawah siswa.

$\mathrm{H} 1$ = Terdapat pengaruh yang signifikan kooperatif tipe STAD terhadap passing bawah siswa.

Kriteria Keputusan:

1) Probabilitas atau nilai Signifikansi $>0,05$, Ho diterima.

2) Probabilitas atau nilai Signifikansi $<0,05$, Ho ditolak

Keputusan:

Terlihat bahwa nilai pada tabel diatas memiliki nilai $t=9.269$ dan Sig $=000<0,05$ maka Ho ditolak, atau dapat pengaruh yang signifikansi kooperatif tipe STAD terhadap keterampilan passing bawah siswa.

\section{PEMBAHASAN}

Berdasarkan hasil pengolahan data dan anilisi diperoleh beberapa temuan, temuan pengujian data menunjukan bahawa terdapat pengaruh model pembelajaran kooperatif STAD terhadap keterampilan passing bawah dalam permainan bola voli. Hasil temuan dilapangan bahwa pembelajaran pendidikan jasmani dengan materi bolabasket yang disajikan melalui pembelajaran kooperatif tipe STAD memberikan kesempatan lebih banyak kepada siswa untuk belajar menguasai tugas gerak yang diberikan oleh guru. Model pembelajaran kooperatif tipe STAD, di setiap pembelajarannya siswa harus terlibat langsung dalam sebuah proses pembelajaran tugas gerak maupun proses sosial dimana siswa bekerja secara bergotong royong demi tercapainya tujuan pembelajaran. Pada proses pembelajaran kooperatif, bukan hanya guru yang memotivasi siswanya agar menyelesaikan tugas gerak dengan baik, tetapi siswa juga ditekankan supaya saling memberi motivasi dan mengajari teman kelompoknya dalam upaya melakukan tugas gerak yang diberikan oleh guru. Hal tersebut senada dengan yang dikemukakan Eggen \& Kauchak dalam (Juliantine dkk, 2013) menyatakan bahwa "pembelajaran kooperatif tipe STAD merupakan sebuah kelompok strategi pengajaran yang melibatkan siswa bekerja secara berkolaborasi untuk mencapai tujuan bersama". Jadi dalam pembelajaran kooperatif siswa berperan ganda yaitu sebagai siswa ataupun guru, dengan bekerja secara berkolaboratif untuk mencapai sebuah tujuan bersama, maka siswa akan 
mengembangkan keterampilan berhubungan dengan sesama manusia yang akan sangat bermanfaat bagi kehidupan di luar sekolah.

Dyson (2001) berpendapat bahwa salah satu manfaat dari pembelajaran kooperatif adalah bahwa siswa belajar untuk menganalisis keterampilan. Artinya bahwa dalam pembelajaran kooperatif terjadi proses kolaborasi dan diskusi antara anggota kelompok, bukan hanya guru yang memberikan feedback positif kepada siswa tetapi juga terjadi pada siswa dikelompoknya masing-masing, dan pada akhirnya setelah melakukan analisa dan diskusi dengan kelompok mereka dapat mengeksekusi keterampilan dengan baik atau dengan kata lain mereka dapat melakukan keterampilan gerak yang benar. Penelitian yang dilakukan Bayraktar (2011) yang menemukan bahwa perlakuan pembelajaran kooperatif dengan materi senam memiliki pengaruh yang lebih baik terhadap keberhasilan akademik siswa dan keterampilan latihan dibandingkan dengan kelompok kontrol, selain itu penelitian yang dilakukan Faozi (2015) yang menemukan bahwa model pembelakaran kooperatif STAD berpengaruh terhadap penguasaan ketarampilan teknik dasar bolabasket.

Dari uraian diatas dapat ditarik kesimpulan bahwa terdapat pengaruh yang signifikan dari model pembelajaran kooperatif tipe STAD terhadap penguasaan keterampilan teknik dasar siswa. Hal ini didasari bahwa penguasaan keterampilan siswa dalam pembelajaran dengan model pembelajaran kooperatif STAD dapat ditingkatkan, karena model pembelajaran kooperatif tipe STAD memberikan tanggung jawab kepada siswa yang belajar secara kelompok untuk menyelesaikan tugas ajar yang diberikan oleh guru secara bersama-sama dan seluruh siswa harus berkontribusi terhadap hasil belajar tersebut. Sehingga siswa yang memiliki kemampuan yang rendah dalam proses pembelajaran akan termotivasi untuk menyelesaikan tugas yang diberikan oleh guru untuk mendapatkan hasil yang lebih baik dan tanpa disadari penguasaan keterampilan menjadi meningkat.

\section{SIMPULAN}

Dari hasil penelitian yang telah dilaksanakan dapat disimpulkan bahwa: "Terdapat pengaruh yang signifikan model pembelajaran kooperatif tipe STAD terhadap hasil belajar passing bawah dalam permainan bola voli di SMA Islam Al-Fardiyatussa'adah Citepus Kecamatan Palabuhanratu". Mengacu pada penelitian, maka peneliti merekomendasikan: Bagi siswa diharapkan siswa harus lebih sering lagi berlatih disekolah maupun di luar sekolah, supaya keterampilan passing bawah lebih meningkat. Dan menambah wawasan pengetahuan khususnya dalam pembelajaran materi passing bawah bola voli. Bagi Guru disarankan kepada guru penjasorkes agar menerapkan model pembelajaran kooperatif khususnya tipe STAD karena terbukti dapat meningkatkan aktivitas dan hasil belajar passing bawah bola voli. Bagi sekolah disarankan kepada sekolah agar model pembelajaran kooperatif dijadikan pedoman dalam 
sebuah pembelajaran khususnya pembelajaran penjasorkes, karena model pembelajaran kooperatif menunjukan kepada siswa agar memiliki rasa tanggung jawab, bekerjasama, dan gotong royong.

\section{REFERENSI}

Aditama, Zainal, dkk. (2014). Penerapan Model Pembelajaran STAD (Student Team Achievement Devision) Terhadap Hasil Belajar Ketepatan Service Bawah Bola Voli. Jurnal Pendidikan Olahraga dan Kesehatan. Volume 02, Nomor 01 tahun 2014, 41-44.

Bayraktar, G. (2011). A the effect of cooperative learning on students'approach to general gymnastics course and academicachievements.Academic Journals, 6 (1), hlm.68-70.

Bakhri, Saepul, Rafdal. (2008). Materi Perkuliahan Statistik. Sukabumi: Sekolah Tinggi Keguruan dan IImu Pendidikan

Juliantine, Tite, dkk. (2015). Model-model Pembelajaran dalam Pendidiakan Jasmani. Bandung: Bintang Warliartika.

Faozi. Faiz (2015). Perbandingan Pengaruh Model Pembelajaran Kooperatif tipe STAD dan Direct Teaching Terhadap Penguasaan Keterampilan Teknik Dasar Bolabasket. Pasca Sarjana UPI : Tidak diterbitkan

Febrianto, dkk. (2018). Pengaruh Model Pembelajaran Kooperatif Tipe STUDENT TEAM ACHIEVEMENT DEVISION (STAD) Terhadap Hasil Belajar Passing Bawah Bola Voli. Jurmal IImiah FKIP Universitas Subang. Volume 4, Nomor 1.

Fauzi. (2011). Penyusunan Battery Test Olahraga Bola Voli.Yogyakarta: Pakultas Ilmu Keolahragaan, Universitas Negeri Yogyakarta.

Metzler, Michael W. (2000). Intructional Model For Physical Education.Massachusetts: Allyn and Bacon, Inc.

Schmidt, R A dan Wrisberg, C A. (2000). Motor Learning and Performance (Second Edition). Human Kinetics:USA

Slavin, Robert E. (2005).Cooperative Learning, London: Allyn and Bacon, Inc.

Stephani, Mesa. Rahmi (2014). Pengaruh Model Pembeljaran Inkuiri Terhadap Kemampuan Berpikir dan Keterampilan bermain Bolabasket. Pasca Sarjana UPI : Tidak diterbitkan

Subroto, Toto, \& Yudiana, Yunyun. (2010). Permainan Bola Voli. Bandung: Universitas Pendidikan Indonesia.

Sugiyono. (2015). Metode Penelitian Pendidikan. Bandung: Alfabeta.

Wang, M (2012). Effect of Cooperative Learning on Achivement Motivation of Female University Student. Asian Social Science: Vol 8. No 15:2012 